\title{
ARAÑA EN BAÑERA Y TERRAZA DE CAFÉ POR LA NOCHE, DE EMMA COHEN
}

\section{ARAÑA EN BAÑERA AND TERRAZA DE CAFÉ POR LA NOCHE, BY EMMA COHEN}

\author{
Eva GARCÍA-FERRÓN \\ Universidad de Alicante \\ eva.ferron@ua.es \\ orcid.org/0000-0002-5590-9153
}

\section{Resumen}

Este trabajo es un acercamiento a la figura de Emma Cohen y a sus dos textos dramáticos para adultos, Araña en bañera y Terraza de café por la noche. Nuestro propósito es comenzar a subsanar la total ausencia de estudios sobre esta artista de curiosidad insaciable cuya creación se diversifica en disciplinas variadas. Las obras a las que nos aproximamos son muy diferentes y, a la vez, representativas ambas del rico universo de Cohen, de sus preferencias literarias, de su estilo. El análisis de estas dos piezas, que no agota esta aportación, nos ofrece un mirador privilegiado para apreciar y entender la creación de la autora.

Palabras clave: Emma Cohen, teatro, monólogo, Surrealismo, lesbianismo.

\begin{abstract}
This work is an approach to the figure of Emma Cohen and her two dramatic texts for adults, Araña en bañera and Terraza de café por la noche. Our purpose is to begin rectifying the complete lack of research on this artist whose insatiable curiosity led her to diversify her creation into different disciplines. The plays that we are researching are significantly different and, at the same time, both of them are representative of the rich universe of the writer, her literary preferences, her style. This contribution does not exhaust the study of these two pieces. However, it offers a privileged viewpoint to appreciate and understand the creation of this author.
\end{abstract}

Keywords: Emma Cohen, theatre, monologue, Surrealism, lesbianism.

Feminismo/s 30, diciembre 2017, pp. 69-92

Los contenidos de la revista se publican bajo una licencia de Creative Commons Reconocimiento 4.0 Internacional (CC BY 4.0) 



\section{EMMA COHEN, «INCAPAZ DE SER SOLO ACTRIZ»}

Emma Cohen es una mujer polifacética, una artista e intelectual relevante dentro del panorama cultural español de la segunda mitad del siglo XX. Sin embargo, al acercarse a su figura sorprende la superficialidad y dispersión de la información relacionada con su actividad profesional. La mayor parte de las referencias a ella y su trabajo proceden de la prensa de los días siguientes a su muerte, ocurrida el 11 de julio de 2016. Compatibilizar el innegable interés de su actividad creadora con esta carencia de estudios y materiales académicos constituye un reto para la investigadora. El objetivo de este trabajo es esbozar una biobibliografía lo más rigurosa posible de la autora y analizar sus textos dramáticos Terraza de café por la noche y Araña en bañera ${ }^{1}$.

Emma Cohen es conocida en España por sus interpretaciones en cine, teatro, radio y televisión; no obstante, fue una mujer extremadamente curiosa, que se aventuró en facetas muy distintas. Su labor literaria, centrada en la narrativa y, en menor medida, en el teatro, fue constante desde que publicó su primera novela en 1983 y casi hasta el final de su vida, pero también se atrevió con la dirección cinematográfica, la escritura de guiones televisivos y radiofónicos, las colaboraciones periodísticas, la docencia escénica, la ilustración y el colaje².

Emmanuela Beltrán Rahola, nacida el 21 de noviembre de 1946 en Barcelona en el seno de una familia burguesa, desde que tenía poco más de veinte años se integró de modo activo y atrevido en la vanguardia social y

1. Agradecemos a Helena de Llanos que nos proporcionara el texto inédito de Araña en bañera. Su deseo y el nuestro es que se visibilice la creación de Emma Cohen, de quien se siente nieta: «...soy nieta de Fernando Fernán Gómez y no llevo su apellido, también soy nieta de Emma Cohen y no llevo su sangre. Me gusta sentir que juntos formamos un triángulo familiar bastardo, tres puntas conectadas en el interior de la casa de mis abuelos, donde ahora vivo» (Llanos).

2. Este interés por el colaje es un indicio de su predilección por el surrealismo. El colaje pictórico fue creado en 1912 por Juan Gris, a quien siguió Picasso con sus "papiers collés». El colaje tenía un propósito estético cubista, pero también pretendía materializar el principio surrealista de situar cosas fuera del lugar al que están destinadas. Señala Francisco Aranda que Max Ernst fue quien «exploraría este filón hasta las últimas consecuencias literarias y psíquicas dentro del surrealismo» (25).

Feminismo/s 30, diciembre 2017, pp. 69-92 
cultural española y europea. Luis Alegre destaca que en Barcelona frecuentó el ambiente de la gauche divine, y más tarde, en Madrid, el mundo de la noche de Oliver o Bocaccio y las tertulias del Café Gijón, «donde su belleza y su gracia surrealista arrasaban». Alegre, que llegó a conocerla personalmente en su madurez, afirma: «Siempre fue rebelde, ácrata, inteligente, chispeante y muy inquieta, incapaz de ser solo actriz».

Cohen estudiaba la carrera de Derecho cuando tuvo su primer contacto con la escena en el TEU (Teatro Estable Universitario). En 1968 viajó a Francia para asistir al Festival de Teatro de Nancy y aprovechó la ocasión para acudir a París, donde vivió el Mayo del 68 codo con codo con los jóvenes franceses, hasta el punto de ser detenida (Bugallal). El texto La libreta francesa. Mayo del 68 es un documento valiosísimo que recoge estas vivencias, un diario de lo que presenció entre el 29 de abril y el 1 de junio en París (Cohen 2008).

La interpretación fue su ocupación principal durante los setenta. En 1973 recibió la Medalla del Círculo de Escritores Cinematográficos a la mejor actriz, y fue en aquellos años cuando la revista Fotogramas la entronizó como «Musa del underground» (Dufour). En el cine fue dirigida por realizadores como Roberto Bodegas, Eloy de la Iglesia, Fernando Colomo, José Luis Garci, Imanol Uribe y José Luis García Sánchez (Alegre). Daniel María subraya que su mayor aportación como actriz a nuestro séptimo arte corresponde «al cine más arriesgado, poético y outsider del panorama español». En cuanto al teatro, participó, entre otros muchos, en dos montajes emblemáticos al comienzo de su carrera: Marat-Sade, dirigido por Adolfo Marsillach en 1968, y Un enemigo del pueblo, estrenado en 1971 bajo la dirección de Fernando Fernán-Gómez (Dufour).

El trabajo de Daniel María «Para la libertad: la literatura de Emma Cohen» es el único que existe sobre la producción literaria de la autora. Señala este que a la primera etapa literaria de Cohen pertenecerían las novelas Toda la casa era una ventana (1983) y Negras tierras negras (1988), así como la narración juvenil Alba, reina de las avispas (1986), protagonizadas todas ellas por mujeres muy jóvenes y niñas. En 1990 publica Hechizos, filtros y conjuros eróticos y el relato juvenil Miranda Hippocampus o La Isla del Aire. Tres años más tarde aparecen las novelas Muerte dulce y Rojo Milady. Tras la publicación de Loca Magnolia en 1996 se abre un paréntesis de quince años en cuanto a su novelística, hasta que en 2011 se edita Ese vago resplandor, «la más ambiciosa de sus narraciones [...], es un ejercicio de ensayo periodístico, novela y autoficción» (María). En 2014 publica su última novela, Magia amorosa para desesperadas y desesperados.

Los textos dramáticos de Emma Cohen son pocos, y solo algunos de ellos están editados. En 2008 publicó una obra infantil, La boca del árbol. Otro texto infantil, Libeliula, que se había estrenado en julio de 2008 en la Exposición 
Internacional de Zaragoza, se editó en 2010. En 2011 publicó Terraza de café por la noche, de la que nos ocupamos a continuación. En cuanto a las inéditas, además de Araña en bañera, Cohen realizó una adaptación de la novela La antesala, de Ramón J. Sender, que lleva por título Nazaria, y una adaptación de Peter Pan para radioteatro (María).

\section{ARAÑA EN BAÑERA Y TERRAZA DE CAFÉ POR LA NOCHE}

Los dos únicos textos dramáticos originales y para público adulto de la autora son una excelente muestra de su audacia, de su deseo de explorar en el terreno del arte y la literatura. Este trabajo aborda un acercamiento a ambos para establecer si hay un sustrato común en ellos y para valorar (en la medida en que lo permite la extensión de lo que sigue) cada uno en su individualidad.

Araña en bañera se estrenó el 17 de noviembre de 2008 dentro de un ciclo SGAE de Lecturas Dramatizadas. La lectura, bajo la dirección de Carmen Losa, tuvo lugar en la sala Manuel de Falla de dicha entidad y fue presentada por Emma Cohen (Artezblai). Esta Tragicomedia de soledades en un acto, según la subtitula la autora, tiene como protagonista a Sofía Espíritu, que inesperadamente es abandonada por su amada, Patri, el día de su cumpleaños y cuando está a punto de ser desahuciada de su casa. Mientras graba un testamento oral en el que lega simbólicas pertenencias de varios ancestros a personas de su entorno, Sofía evoca las trayectorias vitales de sus ascendientes, desde su tatarabuela filipina Sofía hasta su tía Carlota. Esta última, con quien la protagonista tuvo una estrecha relación y en cuya casa transcurre la acción dramática, era también homosexual. Una araña de grandes dimensiones está presente en escena desde el comienzo de la obra. Simboliza la muerte, el deseo o la necesidad de morir.

Terraza de café por la noche fue escrita en 2010 y publicada en 2011 por La Página. La obra, que no ha sido estrenada, toma su título del óleo pintado por Vincent Van Gogh en 1888. Dado el carácter surrealista de la pieza, resulta improcedente sintetizar su argumento. La autora pone en escena a los seres pintados por el holandés, les asigna nombres y les hace dialogar. Hacia el final se suman a estas criaturas Van Gogh y Gauguin (el Joven Van Gogh ha estado en la terraza del café casi desde el comienzo), y se alude a la relación que ambos mantuvieron en Arles. El lenguaje de los diálogos y las acotaciones es elaborado y poético; la dramaturga reconoció que su redacción había sido ardua pero gratificante: «Me resultó de lo más placentero escribirla, complejidades incluidas» (Garrido). El mismo año de la publicación de este texto Cohen pronunció en Tenerife una conferencia titulada «Teatro y literatura en el teatro español de vanguardia», en la que demuestra su saber sobre el tema, su interés específico 
por el surrealismo ${ }^{3}$, su devoción por Antonin Artaud y un conocimiento de los ecos de las vanguardias incluso en autores actuales (Rodrigo García y Angélica Lidell). Es muy estimable la aportación de Cohen para tratar de recuperar un teatro tan olvidado como relevante en la historia literaria de España: «...los dramas escritos durante la época surrealista constituyen la escuela dramática más intelectual, más atrevida artísticamente, más moderna de la España del siglo XX» (Sheklin Davis 350).

Estamos ante dos textos cercanos en el tiempo pero notablemente distintos: Araña en bañera es un monólogo de factura clásica (aunque de contenido contemporáneo) en el que Cohen se sirve de su experiencia como narradora para que la protagonista despliegue sobre las tablas las vidas de varios parientes; Terraza de café por la noche, en cambio, es una sucesión de escenas en las que más de treinta personajes interactúan sin que exista un hilo argumental aparente. No obstante, las dos piezas comparten algunos rasgos, y es posible establecer paralelismos incluso entre sus divergencias. Nos ocupamos a continuación de rastrear ambas cuestiones.

\subsection{Los títulos y los subtítulos}

Las tres primeras palabras de Terraza de café por la noche son dos sustantivos unidos por una preposición y sin artículos, lo cual les confiere un carácter genérico; el sintagma preposicional es igualmente poco concreto. Como ocurre con frecuencia en pintura, el título que Van Gogh eligió para su obra (y que Cohen toma prestado) nos remite, simultáneamente, a cualquier café con terraza de no importa qué noche y a un café y una noche específicos: los que quedan fijados para la posteridad en el lienzo. Asimismo, en Araña en bañera la presencia de dos sustantivos sin determinantes y unidos por una preposición transmite al lector/espectador la imagen de los dos conceptos desnudos, es decir, cualquier araña en cualquier bañera. El título vincula dos elementos que en la vida cotidiana se presentan asociados, pues las arañas prefieren los ambientes húmedos; sin embargo, conforme avanzamos en la lectura descubrimos que ambos son

3. Este interés es un reflejo de su actitud vital. El impacto de este movimiento, expresado por Francisco Aranda en 1981 en estos términos, sigue tan presente como augura el final de la cita: los surrealistas «quisieron operar una revolución en los espíritus y lo consiguieron. [...] asomémonos a la intimidad de un hogar joven, entremos en los recintos de una universidad, observemos las modificaciones en los criterios del comportamiento sexual, [...] reparemos en el arreglo de un escaparate, un cartel, un anuncio publicitario... y por todas partes comprobaremos la presencia de la acción surrealista. No es el surrealismo el único culpable del actual estado de cosas, aunque su contribución ha sido enorme. Conviene seguir vigilándolo, porque su agresión continúa» (18-19). 
símbolos de algo más trascendente: la araña, enorme y acechante, es aquí la muerte, mientras que la bañera representa el hedonismo implícito en un baño en agua caliente y perfumada, es decir, es un epítome de los placeres de la vida, de la vida en definitiva.

En cuanto a los subtítulos, el de Terraza de café es Peripecia soñante, dos palabras elegidas con cuidado por la autora. El sustantivo «peripecia» es definido por el DRAE de este modo: «En el drama o en cualquier otra composición análoga, cambio repentino de situación debido a un accidente imprevisto que altera el estado de las cosas». En el sentir de los hablantes, el término tiene un matiz de aventura, de giro lúdico. El adjetivo «soñante» alude al protagonista formal del texto («Soñante Impactado») al tiempo que anticipa el papel destacado de los sueños, tema eminentemente surrealista, en este.

Araña en bañera es subtitulada por Emma Cohen Tragicomedia de soledades. La obra es tragicómica porque los episodios (y la síntesis que de ellos se destila) de las vidas de sus familiares que nos presenta la mujer que monologa son, como cualquier existencia vivida con intensidad, una mezcla de hechos cómicos y dolorosos. El sustantivo plural «soledades» es también adecuado, ya que los personajes que desfilan por escena son hombres y mujeres con una rica vida social, familiar y amorosa, pero unos y otras viven, por distintas causas (frustraciones, adicciones, preferencias sexuales) dentro de un aislamiento innato que nadie logra franquear.

\subsection{Propósito y sentido}

En Araña en bañera Emma Cohen, profundamente libre, libertaria y feminista, crea, desde la madurez de sus sesenta años, un texto dramático en el que una mujer lesbiana monologa sobre el delicado momento vital que está atravesando. Su soliloquio, pese a ser el preámbulo de su suicidio, se convierte en un alegato a favor de la vida moteado de humor, en una apología del valor de vivir haciendo uso de la libertad personal y del arrojo para superar los obstáculos sociales, económicos o familiares. Los seres humanos cuyas vidas nos pone ante los ojos Sofía Espíritu son, como ella misma, personas lastimadas por su circunstancia, pero que triunfan en su propósito de vivir soberanamente.

El sentido último de Terraza de café revela de modo aun más manifiesto el espíritu rebelde e investigador de Cohen, por su apuesta de actualizar el teatro surrealista en una obra que es un ejercicio de inclusión de la mayoría de los ingredientes propios de esa corriente. Escribir en 2010 una pieza surrealista puede antojarse anacrónico en términos estrictamente teatrales; lo que sucede es que esta escritora, tan ajena a la búsqueda del éxito o la notoriedad pública, persigue un propósito personal: 
El teatro surrealista, lleno de personajes deshumanizados, temas intelectuales, yuxtaposiciones e inconsistencias irracionales, es un ejemplo por excelencia de un arte que excita la hostilidad del espectador común. [...] El surrealismo mismo encierra un principio de incomunicación. (Sheklin Davis 347)

Es cierto que la aproximación a un texto surrealista, incluso para quien lo estudia, presenta dificultades desalentadoras. Pero la escritora halla en el surrealismo un espacio de libertad creadora absoluta, apto para abrazar y transferir un bagaje personal que desbordaría el marco impuesto por un texto más convencional. En la entrevista de Garrido ya mencionada, Cohen expone el fin de Terraza de café: «...significa para mí transmisión, ofrecer a otras personas lo mejor de mí. E imagino que las influencias son incalculables, ya que la diosa curiosidad me ha empujado a ser una consumada lectora y vividora». Esta creación es, por un lado, la realización del deseo de la autora de convertir una tela que la deslumbra en un ente vivo y, por otro, un ejercicio de ensalzamiento de la imaginación en la línea del dogma codificado por Louis Aragon en su obra de 1926 Le Paysan de Paris: "Tout relève de l'imagination et de l'imagination tout révèle» [Todo compete a la imaginación y de la imaginación todo se revela] (Morris 189).

Refiriéndonos todavía a la identificación de Cohen con las vanguardias, la elección del cuadro de Van Gogh como tema de la pieza debe vincularse con la declarada admiración de la dramaturga por Antonin Artaud, quien, en su texto Van Gogh, el suicidado por la sociedad, afirma que el arte del holandés supuso una revolución de dimensiones universales:

Porque la pintura de Van Gogh no se opone a cierto conformismo de las costumbres sino al de las mismas instituciones. Y después del paso de Van Gogh por la tierra, ni la naturaleza exterior, con sus mareas, sus climas y tormentas equinocciales puede conservar la misma gravitación. (4)

\subsection{Asunto y temas}

El tema central de Araña en bañera, como anuncia su subtítulo, es la soledad, rasgo que comparten todos sus personajes. Si bien ninguno de ellos experimenta una soledad externa, en la pieza es visible la desconexión de otros personajes a la que le conducen a cada uno sus flaquezas, sus excentricidades o su inconformismo ante las convenciones. Este inconformismo no alcanza la categoría de rebeldía porque no es así como lo narra la protagonista, Sofía Espíritu; se manifiesta con unos comportamientos que, desde la naturalidad, atropellan lo convencional sin miramientos y conducen a estos seres a menudo a la exclusión. La pieza contiene también, como se verá, un sentido y festivo alegato en favor de la normalización de la homosexualidad femenina. 
Resulta complejo reducir a pocas palabras el asunto de este cuasi monólogo, tantos son los caminos por los que transita la dramaturga. Junto a la soledad, solapándose de hecho con ella, otro eje de la obra lo conforman el amor y el desamor, entre Sofía y su amante, y también entre cuantos hombres y mujeres evoca. Las ideas del suicidio y la muerte no se ausentan en ningún momento del texto, porque la presencia de la araña los connota. Las relaciones familiares (inquebrantables a veces, fragilísimas otras) son asimismo un tema relevante. La vida profesional de los parientes rememorados, varios de ellos artistas, se imbrica con la personal, por lo que el mundo del cine, el teatro y la música es otro de los asuntos tratados. Dado que Sofía tiene ancestros que practicaron el hurto y la estafa, que fueron adúlteros o alcohólicos, ante nuestros ojos comparecen seres humanos que ejemplifican debilidades y vicios de todo tipo. Por último, el sexo sobrevuela toda la acción dramática.

Respecto a Terraza de café, contamos con la voz más autorizada, la de la autora: «La línea argumental es Van Gogh en sí mismo, lo que despierta su obra y su ser» (Garrido). Sin duda, «lo que despierta» la obra y la complejidad artística y personal del holandés es, como formulación de la línea argumental de un texto dramático, deliberadamente abstracta y abarcadora. Cohen define de la mejor forma posible el argumento al verbalizarlo de modo tan difuso. Hay que tener presente que el teatro surrealista supuso un vuelco en los valores dramáticos: los dramas no se escribían ya para relatar historias, sino para escenificar paradojas de significado trascendental o universal. Lo explica, de modo no tan distinto a nuestra autora, Sheklin Davis:

El tema en el teatro surrealista tomaba forma como sentimiento penetrante. Es decir, no era una bien definida idea central, [... ] sino que, como escribe Juan Guerrero-Zamora, trasciende sobre la acción, «la informa de su espíritu, la vuelve sueño, con lo que no es la idea lo que predomina, en el plano de la comunicación, sobre la vivencia, sino la vivencia lo que desenvuelve la idea».

(328-329)

En Terraza de café no hay un desarrollo lógico del argumento ni se indica el fondo de la acción: el elemento esencial es la acción misma. Los personajes no se presentan, simplemente dialogan, y la relación entre causa y efecto se ha eliminado. Con todo, desde la primera escena es perceptible ese «sentimiento penetrante» al que alude Sheklin Davis. Fijémonos en el arranque de la pieza, donde ya se observa lo que ocurrirá a lo largo de toda ella: el discurso racional es sometido a un proceso de dislocación, las palabras se combinan de modos inesperados y el resultado son unos diálogos tan ininteligibles como sugerentes. Tras la hermosa acotación inicial que describe cómo la iluminación muestra progresivamente el callejón, el cielo, la terraza, el edificio del café y la gente 
hasta desvelar el óleo en su totalidad, y cómo del fondo del callejón emerge un joven («en chándal ocre y casco negro», 13) y avanza por la calle empedrada para detenerse donde Van Gogh lo pintara, se producen las primeras intervenciones de los personajes:

NIÑA. - Mira, mamá, un soñante impactado.

El joven sigue con el casco, se recompone el chándal y va hacia la MUJER con

NIÑA sentada frontalmente al fondo del café.

SOÑANTE. - (A la NIÑA) ¿Y mi bicicleta?

La NIÑA se encoge de hombros y señala hacia el callejón pintado en negros.

Tras un breve diálogo entre la Mujer y el Soñante, se inicia otro de réplicas cortas y tono lírico entre la Mujer y la Niña, con alguna intervención esporádica del Soñante:

MUJER. - Ansío vida en ámbar, sirenas serpentinas, musgo, cumbres de coral, encaje de algas, menta, azahar, surtidor de ballenas [...]

NIÑA. - Calcomanías. Cromos. Canicas.

MUJER. - Manhattan. Praderas de colza florida.

NIÑA. - Esponja salina. Selva de bambú.

MUJER. - Teatro Nó.

NIÑA. - Patinadoras chinas. [...]

MUJER. - Sócrates, Cervantes, Shakespeare, Kafka, Rilke, Dostoyevski.

NIÑA. - Poe, Lovecraft, Hesse.

MUJER. - Cancuén, Altamira, Giróvago.

NIÑA. - Petra.

MUJER. - Caléndula. Ópalo. Granate. (14-16)

La obra, como se ha dicho, alude a los temas más afines al surrealismo: los sueños, el amor, el elemento misterioso ${ }^{4} \ldots$ La misma personalidad de Van Gogh es próxima a lo surrealista: consideremos, por ejemplo, que los surrealistas se sintieron fascinados por las mutilaciones, que relacionaban con la forma artística del colaje .

Por encima de esos temas o impregnándolos a todos con su sustancia, se distingue el asunto del conocimiento. Emma Cohen reconocía a propósito de la creación de esta obra su permanente curiosidad personal. Abordar la compleja figura de Van Gogh y cuanto subyace a una pintura suya a través de una obra

4. En el contexto de una creación surrealista, no es fácil aislar ejemplos de presencia de lo misterioso, puesto que lo onírico e ilógico están siempre presentes. Esta acotación sería un caso manifiesto: "Silencio: pasan dos ángeles. Un ángel negro y un ángel blanco cruzan (en diagonal) la escena. De la gran puerta del café, surge el ángel negro, del local iluminado situado a la derecha, el ángel blanco, y ambos pasan por delante del SOÑANTE, casi rozándose en el centro» (33).

5. El final de Terraza de café... contiene una recreación de la automutilación del pintor. 
literaria surrealista implica un deseo de profundización y perspectivismo muy osado. Servirse del prisma del surrealismo para aproximarse a una realidad enriquece nuestra percepción de esta de forma exponencial:

Hoy en día apreciamos sobre todo del surrealismo, no ya solo su técnica, que es una consecuencia de su base filosófica, sino su deseo de eliminar el sistema dualista de conocimiento del ser humano, de abolir las oposiciones entre vida/ muerte, sueño/vigilia, objetividad/subjetividad, etc. (Hernández)

La mirada de Emma Cohen sobre la pintura de Van Gogh se sitúa en un plano superior, original y, en consecuencia, nos proporciona una visión diferente, más ancha, más rica.

\subsection{La lista de personajes}

¿Cómo nos son presentados los personajes en cada uno de estos textos? En Araña en bañera, en la lista de personajes estos figuran por orden de aparición. La autora no hace distinciones entre los que aparecerán físicamente sobre el escenario (Sofía -la protagonista-, Patri -su amada-, Manu y Tricia -los hijos de esta-) y todos los demás, que solo se muestran en el espectáculo «proyectados» a medida que la protagonista va reconstruyendo sus vidas: Bisabuela Sofía, Bisabuelo Alfonso, Margarita Xirgu, Rafael Aguilar, Carlotica de Aguilar, Madre de Sofía, Esférico masculino, Esférico femenino, Esférico mixto y Zeus. La araña también comparece en la lista de personajes y, como el resto, lo hace por orden de aparición. La presencia de figuras masculinas es reducida, puesto que la intención de Cohen es ofrecer un universo predominantemente femenino. Los masculinos son aquí personajes menos poliédricos que los femeninos, y están cargados de defectos que los retratan como seres frágiles y dependientes.

Sofía Espíritu Aguilar es presentada como una mujer «De 30 a 50 años». Esta indeterminación se aplica también a los personajes de la bisabuela Sofía ( Pasados los 40»), el bisabuelo Alfonso («Pasados los 50») y Patri ( «De 30 a 40 años»). Además, la dramaturga nos ofrece una somera información sobre cada una de sus criaturas: la bisabuela Sofía tiene «el pelo muy negro» y es «bellísima»; el bisabuelo Alfonso es «Alto, de voz recia»; Margarita Xirgu aparece «En todo su esplendor». A otros personajes los califica con un único adjetivo: «Apuesto» (Rafael Aguilar), «Dulce» (Carlotica de Aguilar), «Resuelta» (Madre de Sofía), «Agradable» (Patri). Solo se extiende algo más en el caso de la protagonista, Sofía Espíritu Aguilar: «No importa que esté gorda o flaca, a pesar de los pesares, guarda cierto vago resplandor».

En Terraza de café por la noche el elenco se compone de veinte personajes con nombre más «14 esperanzados». La lista se ordena a partir de una 
numeración que la autora ha atribuido a cada figura del cuadro y que el lector puede consultar en una reproducción de este en una de las primeras páginas de la edición. Solo cinco de los personajes tienen nombre propio: Peter Blue, Úrsula de Londres (en realidad Úrsula de Layer, la hija de la patrona de la casa donde vivió en Londres Van Gogh y de la que se enamoró), Rachel (la prostituta de Arles a la que, supuestamente, Van Gogh regaló su oreja cortada a modo de pago), Vincent Van Gogh y Paul Gauguin. El resto de personajes tienen nombres genéricos o descriptivos: Figura Oscura, Bohemia Solitaria, Cochero, etc. Tanto la mezcla de personajes reales e irreales como la falta de individualidad (más obvia en el caso de los segundos) son características del teatro surrealista, como advierte Sheklin Davis:

En efecto, sus personajes no tienen ninguna individualidad; son clasificaciones: El Hijo, El Joven, La señora fatigada, La hermana de la Caridad, etc. Cuando llevan nombres, estos son completamente ordinarios y sin significado [...] Los nuevos dramaturgos no se interesaban en casos individuales; según ellos, los temas universales exigían personajes universales [...] Así el individuo recibía atención solo en cuanto sus emociones, acciones y sentimientos fueran significantes en un sentido general y en otro contexto que el suyo. (344-345)

Si en Araña en bañera Cohen prevé las dificultades que un elenco extenso plantea para la puesta en escena mediante las apariciones de personajes proyectados, en este caso en la misma lista de personajes especifica quién puede hacer doblete: «Ángel negro: Puede encarnarlo uno/a de los esperanzados» o «Rachel: prostituta (misma actriz que interpretó a Úrsula de L.)». El modo de caracterizar a los personajes es similar en ambos textos: mediante la edad, siempre aproximada ( «Andarina Yellow: Entre 18 y 30») o con un par de palabras, incluso una sola («Pelirrojo», «Forzosamente ágil», «Baila de fábula»).

\subsection{Araña en bañera: la araña omnipresente y el triunfo del amor lesbiano}

Al estudiar Araña en bañera lo primero que nos preguntamos es cuál es la identidad o la esencia de esta araña que escolta a Sofía durante toda la representación. En la nómina de personajes es descrita de la siguiente forma: «De tres metros de alto. Gótica, tutsi. Autohinchable.» Esta caracterización nos informa de sus espectaculares dimensiones y aporta dos adjetivos sugerentes: lo «gótico» ofrece las pautas estéticas para la construcción de esta figura; «tutsi» es un guiño exótico para aludir a la negrura del arácnido. Es «autohinchable», puesto que ha de aumentar de tamaño progresivamente al comienzo de la obra y disminuir hasta casi desaparecer al final. Cohen descarta que se muestre en 
escena proyectada: es imprescindible la presencia real de esta alegórica criatura sobre las tablas para mantener la tensión dramática ${ }^{6}$.

Para desentrañar el significado de la araña hemos de rastrear algunas de las alusiones que a ella se hacen a lo largo de la obra. En las primeras páginas alguien llama por teléfono y, cuando la protagonista le menciona la presencia de la araña en la bañera, su interlocutor se refiere a Louise Bourgeois (se deduce de las palabras de Sofía). La conexión estética entre la araña que describe Cohen y las de esta escultora es indudable ${ }^{7}$. La primera alusión al vínculo entre la araña y la muerte la hallamos cuando Sofía se dirige a su hija en el testamento oral que está grabando. A modo de despedida, y para exonerarla de cualquier responsabilidad que pudiera sentir la chica ante el suicidio de su madre, le recalca: «Y que sepas que no me borro por tu culpa: hay una araña en mi bañera y punto». Aunque la frase es críptica, conduce al lector/espectador a asumir la filiación de la araña con la muerte ${ }^{8}$.

Existe en el texto una interacción discontinua pero que se prolonga hasta el final entre la protagonista y esta criatura. Por ejemplo, justo cuando Sofía da principio al relato de su vida amorosa, la araña se comunica con ella de un modo impreciso, como reflejan las acotaciones y las palabras de la protagonista: «(se revuelve contra el insecto, le grita), ipues te esperas!, ¡antes debo arreglar algunas cosillas!». Se diría que el ente la azuza para que cometa el suicidio cuanto antes. Sofía se resiste; las «cosillas» de las que ha de ocuparse son la grabación de su propio testamento y la rememoración de la vida de sus antecesores.

Cada cierto tiempo se alude a la araña mientras se recorre la historia familiar, y estas referencias van intensificando el papel del artópodo como metáfora de la muerte, como cuando Sofía vuelca en una gran copa un frasco de pastillas

6. En Terraza de café por la noche hace una breve aparición una descomunal araña que "avanza por el pasillo central del patio de butacas" y, tras alcanzar el escenario y que algunos de los personajes aludan a ella, "se adentra en la tela [...] se la traga la negritud del callejón» (47-49).

7. Louise Bourgeois (1911-2010) es una pintora y escultora franco-americana cuya dilatada carrera fue reconocida por la comunidad artística cuando contaba con setenta años. El motivo de la araña estuvo presente en su obra desde 1947, fecha en que empezó a dibujarlas, hasta el final de su vida. La mayor de sus esculturas de arañas es Maman (1999), realizada en acero y de casi nueve metros de altura, que se encuentra en el Museo Guggenheim de Bilbao (Museo Guggenheim de Bilbao).

8. Pese a que no nos consta que Cohen conociera la historia del suicidio de Alejandra Pizarnik, es oportuno recordar aquí que, cuando esta se quitó la vida en noviembre de 1972, se hallaron sobre su mesa unos versos: «en el centro puntual de la maraña, / Dios, la araña». Se trataba de una cita literal de un poema de Borges, a cuyo segundo verso se le habían quitado las primeras palabras: «En el centro puntual de la maraña / Hay otro prisionero, Dios, La Araña» (Dalmaroni 3).

Feminismo/s 30, diciembre 2017, pp. 69-92 
y, después de añadir hielo, limón y ron, «deposita la copa recién preparada en lugar visible, cerca de la araña». Es esta, pues, quien «custodia» el brebaje letal. Además, cuando la protagonista invoca, desesperada, a la amante que la ha abandonado para permanecer con su marido, la mención de la araña parece suficiente para que aquella entienda el peligro en que se encuentra: «Patri, me mata la espera. Patri, él no se va a tirar por la ventana. Patri, él no tiene una araña en su bañera».

Estando ya el final de la obra muy próximo, Sofía Espíritu se inclina hacia la araña y le propone bailar con ella. Esa danza parece anunciar el final de la mujer, es el preludio de su suicidio. Mientras bailan, la protagonista (se) pregunta cuál de todos sus antepasados muertos ha enviado al gigantesco emisario de la parca:

¿Quién te manda, querida? [...] ¿El abuelo Alfonso se aburre? [...] ¿Acaso madre sigue sin disfrutar de los hombres? [...] ¿Tita Carlota quiere verme bailar? Déjate abrazar, araña guapa, que te voy a bailar bien bailada. Contigo es fácil, ¡tienes tantos brazos y ahora mismo estás tan suave!

A pesar de que resulta obvia la capitulación de Sofía ante la criatura que la ha estado asediando en el transcurso de la tragicomedia, no es la muerte quien vence en esta batalla sobre las tablas, sino el amor entre dos mujeres.

Sofía, Patri y Carlota, las mujeres con más protagonismo en la pieza, son lesbianas. Al convertirlas en el centro de la historia, la intención de Emma Cohen no es profundizar en el concepto de lesbianismo, aunque el desarrollo de la obra sí subraya cómo la fractura de la norma social heterosexual por parte de estas mujeres genera en su entorno un rechazo y una incomprensión intensos 9 .

Sofía Espíritu Aguilar es, con la araña, el puntal de este texto. El verdadero arranque de la pieza se encuentra varias páginas después de su inicio formal, cuando Sofía rompe la cuarta pared por primera vez (lo hará reiteradamente), ofrece sendas copas a un espectador y una espectadora y, tras hacer el gesto de brindar con ambos, comienza su monólogo: «Antes de amar a Patri estuve casada con un hombre estupendo que de repente me tomó manía y me abandonó. ¡Plas! Se borró de la casa y de mi piel». Sintetiza entonces con crudeza el final de la relación, suponiendo que Federico, su ex, un día cualquiera de su vida en común «me contempló horrorizado a pesar de yo no tener ninguna

9. «El término lesbiana surge de forma diversa a través de muchas trayectorias discursivas en y entre diferentes comunidades (desde la biomedicina hasta la contracultura homosexual) y es cultural e históricamente contingente en grado extraordinario. Además, es activamente controlado, refutado y sometido a revisión en el interior y por las comunidades lésbicas, así como por las distintas agrupaciones subculturales en su seno» (Wilton 70). 
costra y fin, salió de casa para no volver». Tal deserción no impide que Federico desprecie ahora a Patri, la novia de su ex esposa.

Sofía se presenta ante nosotros en la fecha de su cumpleaños, «justo el día en que Patri me abandona del modo más brutal, como una adolescente, en silencio, sin llamar siquiera». La mujer sufre un dolor anímico insoportable y en varios puntos de la obra exhibe unas emociones desbordadas. Tras una llamada del marido de Patri en la que le anuncia que ha amenazado a esta con suicidarse junto a sus hijos si ella los abandona, Sofía, que ha discutido acaloradamente con su rival, cuelga e implora en vano al aparato: «Llama, Patri. Me muero. Llama con lo que sea. No puedo más. ¡Te quiero, te quiero, te quiero, te quiero, te quiero!». Tras esta explosión de sentimientos se repone y retoma el hilo de su discurso: «¿Por dónde andaba?». La acción dramática continúa, pero el sufrimiento de la enamorada abandonada, Sofía, y el de la amenazada, Patri, atraviesa la escena desde ese instante.

En uno de sus intentos de hablar por teléfono con su amada, Sofía Espíritu formula una pregunta de improviso: «Patri, ¿recuerdas Brokeback Mountain? $»^{10}$. La referencia a esa película trae a la mente del lector/espectador, por un lado, la imagen de un amor homosexual imposible o marcado por la desdicha; por otro, a renglón seguido Sofía saca de una de las cajas «una raída piel de vicuña con la que se arropa después de encamarse». Ese objeto, en el que repara la mujer quizá porque los protagonistas de la película son dos vaqueros, será el que traiga al escenario el recuerdo de la tía Carlota.

Carlota es una de las tres hermanas de la madre de Sofía. Su peripecia vital, en cuya narración pesa más su vida personal que su oficio de actriz, es la última de las que nos cuenta la protagonista, confiriéndole así un lugar privilegiado dentro de la narración. Esta tía materna ejerce una poderosa influencia en la biografía de la sobrina.

La descripción física que se hace de ella difiere de la de los personajes femeninos heterosexuales, es más precisa y significativa: «Carlota poseía una belleza adelantada, moderna, nueva. Labios gruesos, ojos grandes, verdes... Y cuando algo no le gustaba de su cuerpo, lo variaba, para sentirse siempre bien...». A diferencia de otras familiares bellas etiquetadas por Sofía como «antiguas», Carlota se proyecta hacia el futuro ya desde su apariencia, y se siente dueña de sí misma incluso frente a las imposiciones de la naturaleza sobre su anatomía.

10. Brokeback Mountain es un largometraje estadounidense dirigido por Ang Lee en 2005. En los años 60, dos jóvenes vaqueros aceptan un trabajo para cuidar ganado en la montaña Brokeback; entre ambos surge una amistad que deriva hacia una relación íntima. Cuando acaba el verano, deben abandonar Brokeback y regresar a sus respectivas vidas.

Feminismo/s 30, diciembre 2017, pp. 69-92 
Tras esta presentación, la sobrina enfatiza la «adoración» que sentía Carlota por su hermana Felicia, muerta a los veintiún años (comenzaba a despuntar como actriz de cine mudo en París) cuando aquella tenía quince. Sofía considera que esa muerte fue el primer hito del camino que condujo a Carlota al lesbianismo; dicho itinerario continuó con una iniciación sexual con un hombre impregnada de violencia y, a partir de ese momento, una evitación de las relaciones heterosexuales:

A esa edad son muy importantes las transferencias y al parecer Carlota se quedó colgada de la muerta. Después Carlota estuvo enamorada de uno que se portó muy mal con ella, la desvirgó de un modo brutal, sórdido, sin placer, sin gracia, y desde entonces nunca volvió a encontrarse del todo con los hombres. Desde entonces tuvo varios novios con los que jamás se acostó. [...] Y así hasta que Carlota se hizo homosexual, amó a las mujeres.

Este trayecto hasta el lesbianismo, condicionado por la veneración a la hermana muerta y por experiencias negativas con hombres, correspondería a una concepción de la opción sexual lesbiana como automodelación:

El paradigma posmoderno de la automodelación, producido por una cosificación más general del yo, del cuerpo, del deseo y (sugeriría) el propio género [...], da lugar a una descripción de la sexualidad lésbica como elección individual motivada por un interés racional por una misma. (Wilton 65)

El amor lesbiano es presentado por Emma Cohen desde una perspectiva de absoluta normalidad, sin dejar traslucir que las relaciones lésbicas tengan nada de peculiar o anómalo respecto a los amores heterosexuales que desfilan por la obra. Por ello, una vez ubicada Carlota en su opción homosexual, el texto expone su vida amorosa con un enfoque y un tono análogos a los empleados para los personajes heterosexuales. Cuando tomó a la sobrina Sofía bajo su tutela andaría Carlota por la treintena y ya vivía con su pareja más estable, tita Pato. A causa de la convivencia con ambas la jovencísima Sofía creció con ideas particulares sobre el amor:

Yo pensaba que el amor natural, el normal, el amor amor, era entre mujeres, que las que se juntaban con hombres lo hacían por conveniencia, sobre todo para tener hijos. (Sofía ríe) Creía en el amor que constataba a mi vera, en el amor de tita Carlota y Pato. Creía en dos mujeres que se amaban gozosamente y sin violencia ${ }^{11}$.

11. La ausencia de violencia dentro de una pareja formada por dos mujeres contrasta, para Sofía Espíritu, con su experiencia respecto a la relación de sus padres, puesto que su progenitor era alcohólico y violento. 
Hay una parte de Araña en bañera que constituye un alegato de Cohen a favor de la normalización de la homosexualidad. La protagonista extrae de una caja una extensa carta manuscrita; cuando la lectura concluya sabremos que fue Carlota quien la escribió. La misiva se abre así: «Madre, madre querida, para que deje de llamarme putalesbiana le envío estos párrafos de El banquete de Platón». Mientras Sofía lee la carta, del espejo que hay en escena surgen, proyectados, tres «seres esféricos» como los descritos por Platón ${ }^{12}$. En las letras se explica que Zeus (Júpiter en el original) decidió, para evitar que estos seres escalaran al cielo y combatieran a los dioses, separarlos en dos, y desde entonces

...las mujeres que provienen de los andróginos aman a los hombres. Pero a las mujeres que provienen de la separación de las mujeres primitivas no les llaman la atención los hombres y se inclinan más a las mujeres. En tiempos presentes, al deseo y persecución de ese antiguo estado se da el nombre de AMOR.

La carta se cierra retomando el inicio: «Ya está, madre, fin de los párrafos referentes a los esféricos descritos por Platón y elegidos por mí con la intención de que deje de llamarme putalesbiana. [...] se despide su hija que la quiere y respeta, Carlota». La muchacha acude a un texto clásico para hacer que su madre asuma la naturaleza de sus sentimientos y deje de dirigirse a ella con términos insultantes. Se produce un choque entre la sensibilidad de la hija, que apela a la filosofía, y la ignorancia e insensibilidad de la madre.

Patri es la tercera lesbiana de la pieza. Sin estarlo físicamente, durante toda la obra está presente, puesto que a través de las llamadas telefónicas y de las palabras de Sofía el lector/espectador va componiendo su retrato, más borroso que el de las otras dos protagonistas y, por ello, sugestivo. Cuando arranca el monólogo solo sabemos que ha abandonado a Sofía de modo súbito e inexplicable. Hacia la mitad del texto, una llamada de su marido nos descubre el motivo inmediato, si bien seguimos sin conocer sus verdaderos sentimientos; Sofía se indigna al escuchar las palabras del esposo de su amante: « $i$ Que le has jurado a Patri que si ella se va conmigo tú te tiras con los chicos por la ventana?». En este instante, la historia ofrece un giro inesperado, y Patri pasa de ser un personaje negativo a la víctima de un espantoso chantaje. Con todo, cuando la protagonista, ya bastante avanzado el texto, llama por accidente a la casa de su novia, esta parece ajena a su angustia: «SOFÍA: ¿Rara?, ¿la voz rara? Desde hace un rato toda yo estoy rara. (Pausa) ¿Qué piensas hacer? (Pausa) ¿No puedes hablar? (Pausa) [...] ¡PATRI!». Se trata de un personaje en apariencia

12. En el discurso de Aristófanes de El banquete se dice que en un principio eran tres los sexos, masculino, femenino y andrógino. Estos seres tenían forma circular, cuatro manos, cuatro pies y dos rostros (Platón).

Feminismo/s 30, diciembre 2017, pp. 69-92 
pasivo o apocado, si bien su valentía será la que propicie el positivo final. Es una mujer que sufre maltrato psicológico por parte de su marido y este hecho determina su conducta.

El desenlace, en el que todo se soluciona felizmente, es inesperado. A lo largo de la obra se nos proporcionan pistas falsas para embaucarnos, todo parece encaminarse hacia el suicidio de la protagonista, porque ella, como el receptor, cree que el abandono de Patri es irreversible. Cuando vemos a Sofía abrazar a la araña y danzar con ella como asumiendo su destino, nos asombra que irrumpan en escena los dos hijos de Patri. Llegan como emisarios de su madre y anuncian a la protagonista que desean vivir con ambas. La araña, metáfora de la muerte, se desvanece en ese instante: «...los chicos no la veían y entonces la araña se ha ido». Patri entra poco después en la casa y las amantes se abrazan. La última acotación se regodea con humor en lo almibarado de este final feliz: «Del telar caen confetis multicolores ignifugos». Mientras las dos mujeres se abrazan suena el tango Volver, cuyas notas se funden con las de El día que me quieras.

\subsection{Terraza de café por la noche: el cuadro de Van Gogh y su materialización dramática ${ }^{13}$}

La relación de Emma Cohen con esta obra y con la figura de su autor comienza en su infancia y se prolonga en el transcurso de los años:

En 1958, cuando tenía 12 años, nos cambiamos de casa en Barcelona. Mis padres me dieron a elegir reproducciones de cuadros para decorar los huecos de un armario. Ahí encontré el lienzo por primera vez. Fue emocionante tener día tras día frente a mí la obra de este maestro que buscaba el interior de la belleza. [...] En 1990, durante una Feria del libro en El Retiro, mientras mi compañero Fernando [Fernán-Gómez] firmaba ejemplares, yo me hacía con

13. En la página web del Museo Kröller-Müller, donde se expone el cuadro, se encuentra esta valiosa información sobre las circunstancias en que se pintó y las observaciones del autor sobre su trabajo: «Van Gogh had intended to make a nocturnal painting for some time. And not one in the conventional manner, in shades of black and grey, but actually with an abundance of colours. Equally unconventional is that he paints this gas-lit terrace of a café in Arles in situ and in the dark, because colours have a different appearance during the day than by night. [...] The most eye-catching aspect is the sharp contrast between the warm yellow, green and orange colours under the marquise and the deep blue of the starry sky, which is reinforced by the dark blue of the houses in the background. Van Gogh was pleased with the effect: 'I believe that an abundance of gaslight, which, after all, is yellow and orange, intensifies blue.' [...] He writes to his sister Wil: 'I enormously enjoy painting on the spot at night.' The fact that he observes keenly is borne out by later astronomical research. He painted the constellations precisely as they appeared on the night of 16 or 17 September 1888» (Kröller-Müller Museum). 
un calendario de reproducciones de Van Gogh y apareció otra vez el cuadro. [...] Coloqué la lámina en el váter porque pensé que la vería la gente al menos una vez. Está claro que fui yo quien más tiempo la observó. (Méndez)

A pesar de que este texto teatral merece un estudio pormenorizado por su complejidad, proponemos aquí un breve examen de dos de sus aspectos más relevantes: el lenguaje y el tema de los sueños.

Se ha de prestar especial atención al lenguaje empleado por la dramaturga porque, como subraya Sheklin Davis, en el teatro surrealista este no sirve para recrear lo real, sino que

...las palabras crean, hacen posible lo imposible, hacen real lo irreal. El lenguaje del teatro surrealista es un lenguaje simbólico de "origen oscuro de índole poética», según Pérez Minik y, según Salvador Dalí, es «el único lenguaje realmente universal... ya que [...] reposa en la consciencia misma de las grandes constantes vitales: el instinto sexual, el sentimiento de la muerte, la noción física del enigma del espacio, etc.» (342)

Conocedora de estas premisas, Emma Cohen crea en esta «peripecia» nuevas e insólitas realidades mediante un uso peculiar de la lengua. En los diálogos encontramos combinaciones de palabras que resultan en imágenes chocantes: «Libélula absorta» (13), «pirámides menguantes abrazadas al viento» (14), «Bosques pelirrojos» (15) o «Relámpago en flor» (15). Las acotaciones contienen en ocasiones especificaciones enigmáticas ( La terraza se difumina a trompicones», 38) o esperpénticas («PETER BLUE pellizca al SONANTE en el pene», 27). En ciertas intervenciones de los personajes el lenguaje versa sobre la pintura con apreciaciones a la vez penetrantes y divertidas: «FIGURA EN NEGRO. - [...] Las figuras en negro sobre negro vivimos en un caos irregistrable. De todos modos sabido es que pintar las figuras en negro roba menos tiempo» (34-35). Por otra parte, en varios pasajes los diálogos toman la forma de enumeraciones caóticas que sumergen al espectador/lector en la sensación de desorden propia de lo onírico.

En Terraza de café, como ocurre a menudo en el teatro surrealista, el registro varía sin razón aparente. En distintos fragmentos predominan el poético, el coloquial, el culto e incluso el científico, o todos ellos se funden en diálogos en los que la combinación de ciertos términos causa un efecto estridente cercano al del teatro del absurdo:

SOÑANTE.- ¡Anhelo bondad!

HOMBRE CON SOMBRERO.- Deje de provocar. Deje de provocar o cambie de sueño. [...]

SOÑANTE.- Busco trabajo.

HOMBRE CON SOMBRERO.- Y dale. En ese caso conteste, empecinado:

¿Seremos inmortales? 
SOÑANTE.- Usted, ustedes, todos los plasmados en esta terraza nocturna de Vicent Van Gogh, en cierto modo ya lo son.

HOMBRE CON SOMBRERO.- Me refiero a una inmortalidad común y plena. SOÑANTE.- Factores de crecimiento, algunas proteínas y antioxidantes parecen tener mucho que ver con el envejecimiento. Tengo entendido que dicha inmortalidad se alcanzará tras una revolución biomédica, cuando podamos inducir la regeneración de órganos en seres humanos [...] (17)

Ni siquiera falta en el texto una incursión en la ruptura total con el lenguaje que propugnaron algunas de las corrientes de las vanguardias; en la réplica de Peter Blue la reprimenda coloquial seguida de la mención al museo donde se exhibe Terraza de café por la noche producen un efecto risible:

ANDARINA YELLOW.- [...] Chst. Catikatú, catikatá, flipgonká tiang kai moai.

PETER BLUE.- (Se vuelve hacia ella) Me repatea que hables así fuera del Rijkmuseum Kröller-Müller.» (27-28)

La dramaturga pone especial cuidado en la escritura de las abundantes y a menudo extensas acotaciones, que son minuciosas al explicar cómo es el espacio escénico y de qué forma se distribuyen y actúan los personajes en él. Se logra así que el lector visualice el montaje de un texto cuya puesta en escena entraña dificultades:

De las quince ventanas con luz pintadas en Terraza de café por la noche por Van Gogh surgen sábanas color esmeralda retorcidas y anudadas. Por ellas se descuelgan varios ESPERANZADOS [...] El COCHERO hace restallar su látigo, el CABALLO cobra movilidad, avanza hasta que la portezuela del carruaje quede a la altura del cuerpo humeante del CAMARERO/A, el COCHERO lo introduce en el vehículo y acto seguido (el humo rojizo fluyendo a través de las ventanillas) mueve al caballo hacia atrás, hasta recalar en la posición inicial. (36-37)

En Terraza de café... la sustancia onírica del surrealismo está muy presente. García Lorca, en El Público, expresó esta cualidad de forma espléndida: «El público tiene sagacidad para descubrirlo todo [...] Romeo puede ser un ave y Julieta puede ser una piedra. Romeo puede ser un grano de sal y Julieta ser un mapa. ¿Qué le importa esto al público?» (478). En efecto, con el surrealismo se desvanecieron los límites entre los sueños y la realidad. En el caso que nos ocupa, una ambientación onírica es óptima para que una pintura cobre vida. El mundo de los sueños anula las reglas lógicas y la autora hace uso de esta licencia para dar libertad a la imaginación. Los ejemplos abundan. Hallamos objetos corrientes que cambian de tamaño y se transforman en entes temibles:

HOMBRE CON SOMBRERO ha desaparecido. De él, sobre la mesa que ocupaba, solo queda su SOMBRERO, igual y distinto: el SOMBRERO ahora es grandísimo. 
MUJER Y NIÑA. - (Semicubiertas por el SOMBRERO GIGANTE, al unísono)

¡Me ahogo! ¡Socorro! (20)

$\mathrm{O}$ un personaje ofrece a su interlocutor que elija a su antojo su género (en el lienzo de Van Gogh no se aprecia si se trata de una figura masculina o femenina):

SOÑANTE.- ¿Eres camarero o camarera?

CAMARERO/A. - Lo que usted prefiera.

SONANTE.- Camarero, prefiero camarero.

CAMARERO/A.- Vale. (20-21)

El Soñante se permite incluso permutar los colores originales de Terraza de café..., una aberración tan inaceptable que acaba con una disculpa:

...se produce un oscuro celérico seguido por un encadenado con trastoque colorístico: donde antes estaban los azules ahora están los amarillos y viceversa. Mismo empedrado. SOÑANTE contempla (desde el suelo) la terraza azul, el cielo amarillo. [...]

SOÑANTE.- Perdón, fue un impulso irresistible. (40)

Hemos señalado que en este texto ninguno de los numerosos personajes es protagonista, ni siquiera Van Gogh; como sucede a menudo en el teatro surrealista, el ambiente, lo que Sheklin Davis denomina «la atmósfera espiritual» de la obra, es el protagonista (331). De todos modos, si alguno de los seres pintados en Terraza de café por la noche actúa como hilo conductor, es aquel al que la dramaturga bautiza como «Soñante Impactado», a cuyos sueños parece pertenecer cuanto vemos en escena ${ }^{14}$. Uno de los personajes lo reconoce expresamente:

PETER BLUE.- ¿¡Qué haces!?

ANDARINA YELLOW.- [...] Hago lo que él sueña que hago. (26)

La complejidad espacio-temporal de la obra es asimismo posible por su carácter onírico: el espacio en el que transcurre la acción es la tela de Van Gogh, como algo atemporal, que pertenece al tiempo en que fue creada, a los años transcurridos desde entonces y a nuestro presente; pero las acciones suceden también en el tiempo y el espacio en los que fue pintado el cuadro.

14. Cohen desveló en una entrevista el origen del personaje y cómo este fue el detonante de una creación que tenía en mente desde mucho antes: «Me pasaba todo el tiempo en casa y entré en el cuadro, a analizarlo y a entenderlo. Me di cuenta de que el muchacho del centro llevaba un casco o de que allí estaban las chicas del can-can, los cafetines, la mesa para esperar a Gauguin e, incluso, el estudio de Van Gogh. [...] Iba un día en metro y en el trayecto Plaza de Castilla-Sol un chico me comentó sus ansias de trabajar. Se me ocurrió incluir a ese muchacho dentro del cuadro y surgió la trama. Parto de que tiene un accidente de bicicleta, aterriza en el lienzo y comienza a pedirles trabajo a los personajes. Claramente surrealista.» (Méndez)

Feminismo/s 30, diciembre 2017, pp. 69-92 


\section{CONCLUSIONES}

Como objeto de investigación, la creación dramática de Emma Cohen supone un reto. La ausencia de bibliografía y la desaparición física de la autora multiplican las dificultades, pero también la curiosidad de quien se acerca a su particular concepción teatral. La dramaturga conoce el mundo del teatro desde dentro, y construye sus textos activando resortes que garantizan tanto la empatía del receptor hacia los personajes como una puesta en escena acorde con su proyecto dramático. Es una mujer de cultura vasta y heterodoxa que ha vivido intensamente, y dispone, por un lado, de un conocimiento sobre corrientes estéticas que le permite crear un texto dramático surrealista, Terraza de café por la noche, al que dota de su sello personal; por otro lado, posee una sabiduría sobre la condición humana que plasma en Araña en bañera en personajes cuya autenticidad emana de su intensa forma de entristecerse o disfrutar en función de los avatares de sus vidas. Los asuntos principales o secundarios de su creación dramática (el arte, el amor, la soledad, la libertad o los sueños) son tan universales y atemporales que cualquier espectador/a se sentirá concernido/a por ella.

\section{REFERENCIAS BIBLIOGRÁFICAS}

Alegre, Luis. «Muere la actriz Emma Cohen a los 69 años». El País, 15 julio 2016. <http://cultura.elpais.com/cultura/2016/07/11/actualidad/1468270314_935058.html>, consultado el 10-03-2017.

Aranda, Francisco. El surrealismo español. Barcelona: Editorial Lumen, 1981.

Artaud, Antonin. Van Gogh, el suicidado por la sociedad. Colegio de Bachilleres (Gobierno de México). <https://www.cbachilleres.edu.mx/Bibliowiki/libros/A/ Artaud\%20Antonin\%20Van\%20Gogh\%20\%20el\%20suicidado\%20por\%20 la\%20sociedad.pdf>, consultado el 12-05-2017.

Artezblai. «Lectura de Araña en bañera de Emma Cohen». Artezblai, 14 noviembre 2008. <http://www.artezblai.com/artezblai/index.php?option=com_content\& Itemid $=53 \&$ lang $=$ es $\&$ limit $=20 \&$ limitstart $=9400 \& v i e w=$ archive $>$, consultado el 12-04-2017.

Bugallal, Isabel. «Me pasé quince años gorda para no hacer cine y cuidar a Fernando». La Nueva España [Oviedo], 25 febrero 2012. <http://www.lne.es/ cultura/2016/07/11/pase-quince-anos-gorda-cine/1955116.html>, consultado el 20-04-2017.

Cohen, Emma. La libreta francesa. Mayo del 68. En Dossiers feministes 12 (2008). Mayo del 68: revolución y género. <http://www.e-revistes.uji.es/index.php/dossiers/article/view/647>, consultado el 27-02-2017. 
Cohen, Emma. Terraza de café por la noche. Tenerife: La Página, 2011.

Cohen, Emma. Araña en bañera. Inédito.

Dalmaroni, Miguel Ángel. «Sacrificio e intertextos en la poesía de Alejandra Pizarnik». Orbis Tertius 1 (1996): 1-17. <http://www.orbistertius.unlp.edu.ar/ article/download/OTv01n01a07/4298/0>, consultado el 14-05-2017.

Dufour, Nuria. «Talento natural». AISGE Noticias, 12 julio 2016. <http://www. aisge.es/muere-emma-cohen>, consultado el 4-01-2017.

García Lorca, Federico. El Público. En Obras completas. Vol. 2. Madrid: Aguilar, $1974^{18} .461-487$.

Garrido, Benito. «Entrevista con Emma Cohen: Terraza de café por la noche». Culturamas, 10 junio 2011. <http://www.culturamas.es/blog/2011/06/10/ entrevista-con-emma-cohen-\%E2\% 80\% 9 Cterraza-de-cafe-por-lanoche $\%$ E2\%80\%9D/>, consultado el 4-08-2017.

Guggenheim Bilbao. «Louise Bourgeois. Estructuras de la existencia: las celdas». $<$ https://www.guggenheim-bilbao.eus/guia-educadores/mama/>, consultado el 17-04-2017.

Hernández, Patricio. «El surrealismo español entre la recuperación y la marginación». Cuadernos del Marqués de San Adrián: revista de humanidades 1 (2001): 163-170. <https://qinnova.uned.es/archivos_publicos/qweb_paginas/4469/ revistalarticulo9.pdf>, consultado el 31-07-2017.

Kröller-Müller Museum. «Caféterras bij nacht (Place du Forum)». <http://krollermuller.nl/en/vincent-van-gogh-terrace-of-a-cafe-at-night-place-du-forum-1>, consultado el 15-02-2017.

Llanos, Helena de. (2016) «¡Feliz cumpleaños, Emma!». El asombrario \& Co. 21 noviembre 2016. <http://elasombrario.com/feliz-cumpleanos-emma/>, consultado el 1-05-2017.

María, Daniel. «Para la libertad: la literatura de Emma Cohen». La Galla Ciencia, 13 marzo 2016. <http://literaturaycine.lagallaciencia.com/2016/03/recomendacion-61-la-literatura-de-emma.html>, consultado el 10-01-2017.

Méndez, José D. «Emma Cohen elige la Escuela de Actores para representar su nueva obra». El Día [Tenerife] 6 mayo 2011. <http://web3.eldia.es/2011-05-06/ cultura/cultura2.htm>, consultado el 11-08-2017.

Morris, Cyril Brian. El surrealismo y España. 1920-1936. Madrid: Espasa Calpe, 2000.

Platón. Diálogos: Fedón, o de la inmortalidad del alma; El Banquete, o del amor; Gorgias, o de la retórica. Alicante: Biblioteca Virtual Miguel de Cervantes, 2005. (Edición digital basada en la 18. ${ }^{a}$ edición de Madrid: Espasa Calpe, 1975) $<$ http://www.cervantesvirtual.com/obra/dialogos-fedon-o-de-la-inmortalidaddel-alma-el-banquete-o-del-amor-gorgias-o-de-la-retorica--0/>, consultado el 11-05-2017.

Feminismo/s 30, diciembre 2017, pp. 69-92 
Sheklin Davis, Bárbara. «El teatro surrealista español». El surrealismo. Ed. Víctor García de la Concha. Madrid: Taurus, 1982. 327-351.

Wilton, Tamsin. [Des]orientación sexual. Género, sexo, deseo y automodelación. Barcelona: Bellaterra, 2005. 